\title{
Policy and practices for the ASEAN Community offenders
}

\author{
*Krisanaphong Poothakool and Aranee Vivatthanaporn \\ *President, Institute of Criminology and Justice Administration, Rangsit University \\ Senior lecturer, Royal Police Cadet Academy, Thailand \\ E-mail: k.poothakool@rsu.ac.th
}

\begin{abstract}
In Thailand, more than sixty percent of offenders are involved with drug offenses and around thirty percent are rearrested. It remains a major problem to prevent recidivism and change their habits. Those offenders are not only Thai people but also foreigners from ASEAN countries, especially from those bordering Thailand such as the Republic of Myanmar or Burma, the Lao People's Democratic Republic or Lao and Cambodia. Significantly, foreign offenders from neighboring countries tend to be increased over the past five years. It is accepted that treatment program for the foreign offenders is vital to be initiated. The Department of Probation under the Ministry of Justice has agreed to create strategic plan and set up measures as well as guidelines for the conduct of the offenders in the countries of the ASEAN Community.

This study funded by the Department of Probation aims to explore dilemmas and obstacles to deal with foreign offenders from ASEAN community, to create training program for criminal justice officers in response to the ASEAN community offenders and to propose the policies for the development of training program.

The study used qualitative method. Interviews and focus group were implemented. The interviews were made at policy and operational level. These included the policy makers of the Ministry of Justice, the head of the Department of Probation, practitioners as well as academics.

The research findings can be summarized as follows: 1) The differences in culture, tradition and languages among ASEAN community members seem to be problematic 2) Treatment and rehabilitation program have not been effectively implemented yet. The majority of offenders among ASEAN community lacks understanding about probation process. 3) The development of database and information system for foreign offenders has not been linked from the beginning of the criminal justice process to the end 4) Training system should be established from the top to the bottom, along with evaluation mechanism 5) Human right and human dignity should be a main concern for the officials working at all level.
\end{abstract}

Key words: ASEAN community, probation, drug 